\title{
DOSES DE FÓSFORO, POTÁSSIO E ESPAÇAMENTOS ENTRE LINHAS ALTE- RAM O TEOR DE PROTEÍNA EM GRÃOS DE GUANDU
}

\section{PHOSPHORUS AND POTASSIUM DOSES AND ROW SPACINGS ON CRUDE PROTEIN CONTENTS IN PIGEONPEA GRAINS}

\author{
Danila Comelis BERTOLIN ${ }^{1}$ \\ Marco Eustáquio de SÁ ${ }^{2}$ \\ Salatiér BUZETT| ${ }^{3}$ \\ Letícia Lisboa OLIVEIRA ${ }^{4}$ \\ Elielda Mariane LOPES ${ }^{4}$
}

\begin{abstract}
RESUMO
O presente trabalho teve por objetivo avaliar o efeito de cinco doses de fósforo e quatro doses de potássio em dois espaçamentos entre linhas sobre o teor de proteína dos grãos de guandu de ciclo curto produzidos, em Selvíria, Estado do Mato Grosso do Sul, com semeadura em janeiro de 2005. Para a determinação do efeito dos tratamentos foi utilizado o delineamento inteiramente casualizado, em fatorial $2 \times 5 \times 4$, com quatro repetições, sendo os tratamentos 30 e $50 \mathrm{~cm}$ entre linhas, 0, 40, 80, 120 e $160 \mathrm{~kg} \mathrm{ha}^{-1} \mathrm{de}_{2} \mathrm{O}_{5}$ e 0, 30, 60 e $90 \mathrm{~kg} \mathrm{ha}^{-1} \mathrm{de} \mathrm{K}_{2} \mathrm{O}$. Os tratamentos influenciaram tanto o teor de proteína bruta dos grãos quanto o rendimento de proteína. O espaçamento de $50 \mathrm{~cm}$ e a dose de $40 \mathrm{~kg} \mathrm{ha}^{-1}$ de $\mathrm{P}_{2} \mathrm{O}_{5}$ proporcionaram incremento no teor de proteína. O espaçamento de $30 \mathrm{~cm}$, a dose de $120 \mathrm{~kg} \mathrm{ha}^{-1}$ de $\mathrm{P}_{2} \mathrm{O}_{5}$ e a dose de $60 \mathrm{~kg} \mathrm{ha}^{-1}$ de $\mathrm{K}_{2} \mathrm{O}$ proporcionaram maior rendimento de proteína.
\end{abstract}

Palavras-chave: Cajanus cajan L. Millsp.; rendimento de grãos.

\begin{abstract}
The present work had for objective to evaluate the effects of five phosphorus doses and four potassium doses in two plant spacings inter row in protein contents grains of short-duration pigeonpea, in Selvíria, State of Mato Grosso do Sul, with sowing in januare of 2005. For the treatments effect determination, in a $2 \times 5 \times 4$ factorial was used a completely randomized block design, with four replications, being treatments 30 and $50 \mathrm{~cm}$ plant spacings inter row, $0,40,80,120$ and $160 \mathrm{~kg} \mathrm{ha}^{-1}$ of $\mathrm{P}_{2} \mathrm{O}_{5}$ and $0,30,60$ and $90 \mathrm{~kg} \mathrm{ha}^{-1}$ of $\mathrm{K}_{2} \mathrm{O}$. The treatments influence in crude protein. The space of $50 \mathrm{~cm}$ and $40 \mathrm{~kg} \mathrm{ha}^{-1}$ of $\mathrm{P}_{2} \mathrm{O}_{5}$ improve the crude protein. The space of $30 \mathrm{~cm}, 120 \mathrm{~kg} \mathrm{ha}^{-1} \mathrm{P}_{2} \mathrm{O}_{5}$ dose and $60 \mathrm{~kg}^{-1} \mathrm{~K}_{2} \mathrm{O}$ dose increase the yield protein.

Key-words: Cajanus cajan L. Millsp.; yield.
\end{abstract}

\footnotetext{
${ }^{1}$ Engenheira Agrônoma, Mestranda, Bolsista CAPES. Departamento de Fitotecnia, Tecnologia de Alimentos e Sócio-Economia, Faculdade de Engenharia, Universidade Estadual Paulista (Unesp), Campus de Ilha Solteira. Cx.Postal 31, 15385-000, Ilha Solteira, São Paulo, Brasil. E-mail: dcbertolin@aluno.feis.unesp.br. Autora para correspondência.

${ }^{2}$ Engenheiro Agrônomo, Doutor em Agronomia, Professor do Departamento de Fitotecnia, Tecnologia de Alimentos e Sócio-Economia, Faculdade de Engenharia, Universidade Estadual Paulista (Unesp), Campus de llha Solteira.

${ }^{3}$ Engenheiro Agrônomo, Doutor em Agronomia, Professor do Departamento de Fitossanidade, Engenharia Rural e Solos, Faculdade de Engenharia, Unesp, Campus de Ilha Solteira. Ilha Solteira, São Paulo, Brasil.

${ }^{4}$ Engenheira Agrônoma, Mestranda, Bolsista CAPES. Departamento de Fitotecnia, Tecnologia de Alimentos e Sócio-Economia, Faculdade de Engenharia, Universidade Estadual Paulista (Unesp), Campus de Ilha Solteira
} 


\section{INTRODUÇÃO}

O guandu ocupa o quinto lugar em importância alimentar dentre as leguminosas de grãos (HAAG, 1986), sendo considerada a mais importante leguminosa de grãos depois do grão de bico na Índia (SCHARMA, 1981). É uma fonte rica em proteínas tanto para uso humano quanto animal (WUTKE, 1987). Na alimentação humana tem sido utilizado através do consumo de sementes ou farináceos, os quais se mostram ricos em proteínas, vitamina $B$, caroteno, ácido ascórbico e carboidratos (TEIXEIRA et al., 1985). O guandu pode ser consumido ainda na forma de grãos verdes ou maduros, "dahl" (onde os grãos são descascados) e também in natura (SEIFFERT et al., 1988).

Segundo WUTKE et al. (1998) o espaçamento entre linhas deve variar de 50 a 100 $\mathrm{cm}$ dependendo da época de semeadura, com espaçamentos mais amplos no período tradicional, e mais estreitos em semeaduras tardias. Muitos fatores podem afetar o teor de proteína bruta das plantas, como adubação e a calagem do solo. Para que 0 guandu possa se desenvolver satisfatoriamente há necessidade de calcário e de fósforo já que não se tem bom crescimento em solos ácidos (SEIFFERT e THIAGO 1983). Em observações de OGUNWALE e OLANIYI (1978) e também de AHLAWAT e SARAF (1981) houve um desenvolvimento vigoroso do guandu pela adição de fósforo. JONES e FREITAS (1970) constataram que a omissão de fósforo e de potássio na adubação acarretou diminuição de nitrogênio em leguminosas forrageiras. A importância do potássio para as plantas é devido às suas diversas funções, participando de processos osmóticos, da síntese de proteínas, da abertura e fechamento de estômatos, da permeabilidade da membrana, do controle do $\mathrm{pH}$ e da ativação de cerca de 60 sistemas enzimáticos (MALAVOLTA et al., 1997). HONDA e HONDA (1990) afirmam que teores adequados de potássio aumentam a capacidade das plantas de utilizarem o nitrogênio para transformá-lo em proteína. Observa-se geralmente que o guandu responde menos aos fertilizantes em relação à outras culturas das regiões semi-áridas dos trópicos. Esta falta aparente de problemas nutritivos talvez seja o motivo da realização de poucos estudos sobre a nutrição mineral desta espécie (JOHANSEN, 1990).

Segundo SEIFFERT (1988), os teores de proteína bruta do guandu variam entre as variedades, entre os cortes e épocas do ano, de um mínimo de $130 \mathrm{~g} \mathrm{~kg}^{-1}$ a um máximo de $202 \mathrm{~g} \mathrm{~kg}^{-1}$, VALARINI e GODOY (1994) encontraram valores de 150 a $170 \mathrm{~g}$ $\mathrm{kg}^{-1}$ de proteína na matéria seca. LOURENÇO e DELISTOIANOV (1993) encontraram teores entre 180 a $255 \mathrm{~g} \mathrm{~kg}^{-1}$ de proteína bruta nas folhas do guandu disponível como banco de proteína, o que evidencia a alta qualidade da forragem.

A literatura apresenta dados variados de proteína bruta em grãos de guandu, SINGH e JAMBUNATHAN (1981) observaram que o grão integral de guandu apresenta 211 a $281 \mathrm{~g} \mathrm{~kg}^{-1}$, BARCELOS et al. (1999) utilizando IAC Fava larga obtiveram $250 \mathrm{~g} \mathrm{~kg}^{-1}$, MIZUBUTI et al. (2000) encontraram teor de $257,3 \mathrm{~g} \mathrm{~kg}^{-1}$ utilizando IAPAR 43-Aratã. De acordo com SALUNKE et al. (1986) a proteína do grão de guandu pode variar de 155 a $288 \mathrm{~g} \mathrm{~kg}^{-1}$, sendo influenciada pelos fatores genéticos, ambientais, grau de maturidade e práticas culturais.

Considerando-se a escassez dos dados de pesquisa sobre produção e rendimento de proteína em grãos de guandu e tendo em vista a necessidade do conhecimento das respostas desta leguminosa em relação à adubação e espaçamentos, o objetivo do presente estudo foi verificar os efeitos de doses de fósforo, potássio e espaçamentos entre linhas no teor de proteína dos grãos de guandu (Cajanus cajan L. Millsp).

\section{METODOLOGIA}

O experimento de campo foi realizado na Fazenda Experimental de Ensino e Pesquisa (FEP), localizada no município de Selvíria-MS, coordenadas geográficas de $20^{\circ} 22^{\prime} \mathrm{S}$ e $51^{\circ} 22^{\prime} \mathrm{W}$, e altitude média de $335 \mathrm{~m}$. O clima da região é do tipo Aw, segundo a classificação de KÖEPPEN e, de acordo com informações de HERNANDEZ et al. (1995), a temperatura e a precipitação média anual são de aproximadamente $23,5{ }^{\circ} \mathrm{C}$ e $1370 \mathrm{~mm}$ respectivamente. Neste experimento não foi utilizado sistema de irrigação e a precipitação e a temperatura média ocorridas durante o ciclo da cultura foi de $103,5 \mathrm{~mm}$ e $26^{\circ} \mathrm{C}$. O solo da área experimental é do tipo Latossolo Vermelho Distrófico típico argiloso, A moderado, hipodistrófico, álico, caulinítico, férrico, compactado, muito profundo, moderadamente ácido (EMBRAPA, 1999). As características químicas do solo da área experimental são: $\mathrm{P}$ resina $7 \mathrm{mg} \mathrm{dm}^{-3}$; M.O. $22 \mathrm{~g} \mathrm{dm}^{-3}$; $\mathrm{pH} \mathrm{CaCl}, 5,1 ; \mathrm{K}, \mathrm{Ca}, \mathrm{Mg}$ e $\mathrm{H}+\mathrm{Al}$ respectivamente 1,$4 ; 34 ; 14$ e $28 \mathrm{mmolc} \mathrm{dm}^{-3}$; V $64 \%$.

O solo foi preparado convencionalmente, com uma aração e duas gradagens. A semeadura foi realizada manualmente em 18 de janeiro de 2005, com 20 sementes por metro de sulco, conforme as recomendações de WUTKE et al. (1998). Foram utilizadas sementes fiscalizadas de guandu cultivar IAPAR-43 Aratã, de ciclo curto.

Os tratamentos foram constituídos de dois espaçamentos entre linhas $(30$ e $50 \mathrm{~cm})$; cinco doses de fósforo $\left(0,40,80,120\right.$ e $160 \mathrm{~kg}$ de $\mathrm{P}_{2} \mathrm{O}_{5}$ ha$\left.{ }^{1}\right)$; e quatro doses de potássio $(0,30,60$ e $90 \mathrm{~kg}$ de $\mathrm{K}_{2} \mathrm{O} \mathrm{ha}^{-1}$ ). Como fonte de nutrientes foram utilizados o superfosfato triplo e o cloreto de potássio. Foi utilizado o delineamento em blocos casualizados com quatro repetições em fatorial $2 \times 5 \times 4$, totalizando 40 tratamentos e 160 parcelas que constituíram-se de 5 linhas de $6 \mathrm{~m}$ de comprimento.

Foram colhidas e pesadas 10 plantas da linha central de cada parcela de onde foram extraídos os grãos destinados à quantificação do teor de proteína. Secos e pesados os grãos foram moídos em moinho tipo Wiley, obtendo-se a farinha de guandu com casca, que posteriormente foi utilizada para a determinação do teor de proteína. 0 teor de proteína bruta foi determinado pela decomposição das proteínas e outros componentes nitrogenados na presença de $\mathrm{H}_{2} \mathrm{SO}_{4}$ concentrado a quente, segundo o método Semi-micro Kjeldahl, multiplicando-se o valor do $\mathrm{N}$ total pelo fator 6,25 (A.O.A.C., 1995). O rendimento de grãos foi obtido pesando-se os grãos da segunda linha inteira de cada parcela, sendo os resultados transformados 
em $\mathrm{kg} \mathrm{ha}^{-1}$, e o rendimento de proteína por hectare foi obtido multiplicando-se o rendimento de grãos pelos percentuais de proteína bruta encontrados para cada tratamento.

Utilizou-se o programa SANEST (ZONTA e MACHADO, 1991) para realização das análises estatísticas. Para comparação das médias e verificação dos efeitos de espaçamentos foi realizado o teste de Tukey e para o efeito de doses foram realizadas análises de regressão polinomial conforme BANZATTO e KRONKA (2006).

\section{RESULTADOS E DISCUSSÃO}

As plantas emergiram 6 dias após a semeadura e o ciclo da cultura foi de 150 dias. As porcentagens obtidas para teor de proteína bruta de grãos variaram de $220 \mathrm{~g} \mathrm{~kg}^{-1}$ à $260 \mathrm{~g} \mathrm{~kg}^{-1}$ de acordo com os tratamentos, valores próximos foram encontrados por MIZUBUTI et al. (2000) trabalhando com a mesma cultivar.

$\mathrm{Na}$ Tabela 1 são apresentados os valores médios obtidos, teste de Tukey e regressões referentes a quantidade de proteína dos grãos e ao rendimento de proteína dos grãos de guandu. $\mathrm{O}$ espaçamento de $50 \mathrm{~cm}$ proporcionou incremento de proteína nos grãos superior ao espaçamento de $30 \mathrm{~cm}$, no entanto no espaçamento de $30 \mathrm{~cm}$ entre linhas foi obtido maior rendimento de proteína em relação ao espaçamento de $50 \mathrm{~cm}$.

TABELA 1 - Valores médios obtidos, teste de Tukey e regressões referentes a quantidade de proteína e ao rendimento de proteína dos grãos de guandu. Selvíria, MS, 2005.

\begin{tabular}{|c|c|c|c|}
\hline \multicolumn{2}{|l|}{ Tratamentos } & $\begin{array}{l}\text { Proteína } \\
\left(\mathrm{g} \mathrm{kg}^{-1}\right)\end{array}$ & $\begin{array}{l}\text { Rendimento de Proteína } \\
\left(\mathrm{kg} \mathrm{ha}^{-1}\right)\end{array}$ \\
\hline & 30 & $232,3 \mathrm{~B}$ & $736,13 \mathrm{~A}$ \\
\hline Espaçamento entre linhas (cm) & 50 & $246,7 \mathrm{~A}$ & $650,94 \mathrm{~B}$ \\
\hline \multirow{5}{*}{ Fósforo (kg ha $\left.{ }^{-1}\right)$} & 0 & $242,0^{(1)}$ & $519,74^{(3)}$ \\
\hline & 40 & 248,0 & 679,64 \\
\hline & 80 & 246,7 & 766,54 \\
\hline & 120 & 238,2 & 780,43 \\
\hline & 160 & 222,4 & 721,31 \\
\hline \multirow{4}{*}{ Potássio $\left(\mathrm{kg} \mathrm{ha}^{-1}\right)$} & 0 & $239,4^{(2)}$ & $609,85^{(4)}$ \\
\hline & 30 & 229,0 & 730,44 \\
\hline & 60 & 234,2 & 753,83 \\
\hline & 90 & 255,3 & 680,01 \\
\hline \multicolumn{2}{|l|}{ CV (\%) } & 8,32 & 27,82 \\
\hline \multicolumn{2}{|l|}{ DMS Tukey (5\%) } & 0,62 & 60,34 \\
\hline \multicolumn{4}{|c|}{$\begin{array}{l}\text { (1) } y=-0,0002 x^{2}+0,0239 x+24,2\left(R^{2}=0,69\right) \\
y=0,00087 x^{2}-0,06 x+23,94\left(R^{2}=0,88\right) \\
\text { (3) } y=-0,0228 x^{2}+4,91 x+519,74\left(R^{2}=0,95\right) \\
\text { (4) } y=-0,054 x^{2}+5,6399 x+609,85\left(R^{2}=0,74\right)\end{array}$} \\
\hline
\end{tabular}

O adubo potássico apresentou incremento no rendimento de proteína até a dose de $60 \mathrm{~kg} \mathrm{ha}^{-1}$, ainda com a maior dose do adubo utilizada obtevese $255,3 \mathrm{~g} \mathrm{~kg}^{-1}$ de proteína bruta. Este resultado corrobora com HONDA e HONDA (1990) sendo que o aumento das doses de potássio contribui para o aumento do teor de proteína nos grãos.

STODDART e SMITH (1955) consideram que há uma relação direta entre as quantidades de fósforo e proteína, sendo assim um baixo teor de proteína pode estar associado a um baixo teor de fósforo. Neste trabalho o resultado máximo para quantidade proteína dos grãos foi obtido com a utilização da menor dose, no entanto o maior resultado em rendimento de proteína foi obtido utilizando-se a dose de $120 \mathrm{~kg} \mathrm{ha}^{-1}$.

A Figura 1 apresenta o desdobramento das interações entre as doses de potássio e o espaçamento de $30 \mathrm{~cm}$, sendo $260 \mathrm{~g} \mathrm{~kg}^{-1}$ a produção de proteína resultante da interação entre este espaçamento e a dose de $90 \mathrm{~kg} \mathrm{ha}^{-1}$ de potássio.

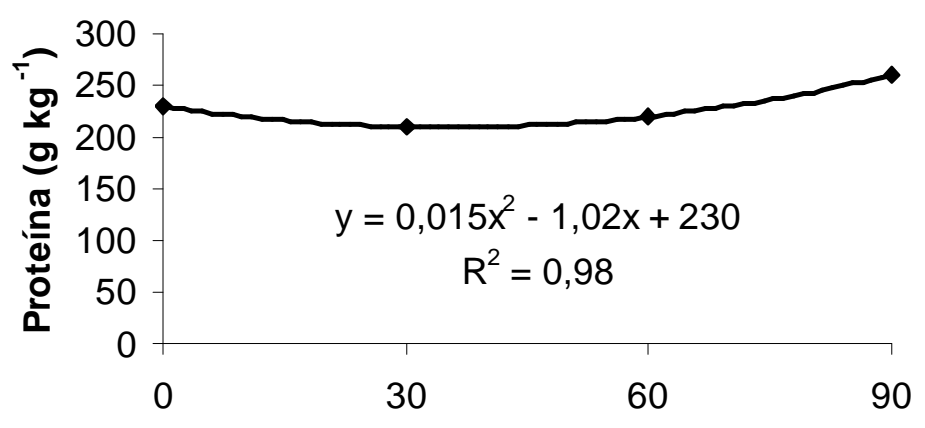

Doses de Potássio (kg ha $\left.{ }^{-1}\right)$

FIGURA 1 - Desdobramento das interações entre doses de potássio e o espaçamento de $30 \mathrm{~cm}$ na porcentagem de proteína dos grãos de guandu. Selvíria, MS, 2005. 
Neste experimento foi obtido um rendimento médio de grãos de $3,1 \mathrm{t} \mathrm{ha}^{-1}$, sendo que os tratamentos também influenciaram significativamente esta variável com a dose de 120 $\mathrm{kg} \mathrm{ha}^{-1}$ de $\mathrm{P}_{2} \mathrm{O}_{5}$ e $60 \mathrm{~kg} \mathrm{ha}^{-1}$ de $\mathrm{K}_{2} \mathrm{O}$ apresentando incremento, superior ao apresentado pelas demais doses, na produtividade. O espaçamento inferior proporcionou maior rendimento de grãos, fato que pode ser atribuído à densidade de plantas que foi superior em relação ao espaçamento de $50 \mathrm{~cm}$. Também SCHAMNE et al. (2001) obtiveram rendimento de grãos de feijão superior no menor espaçamento quando estudaram os espaçamentos de $30,40,50$ e $60 \mathrm{~cm}$.

A Figura 2 apresenta o desdobramento das interações entre doses de potássio e o espaçamento de $30 \mathrm{~cm}$ no rendimento dos grãos de guandu. $A$ interação entre este espaçamento e a dose de $90 \mathrm{~kg} \mathrm{ha}^{-1}$ de potássio proporcionou rendimento de proteína de $826 \mathrm{~kg} \mathrm{ha}^{-1}$.

Houve interação significativa também entre as doses de potássio e a dose de $40 \mathrm{~kg} \mathrm{ha}^{-1}$ de fósforo no rendimento de proteína dos grãos de guandu (Figura 3), tendo a combinação desta dose de fósforo com a dose de $60 \mathrm{~kg} \mathrm{ha}^{-1}$ de potássio proporcionado rendimento de $825 \mathrm{~kg} \mathrm{ha}^{-1} \mathrm{de}$ proteína. A interação entre as doses dos adubos se mostrou interessante em relação ao efeito dos adubos estudados isoladamente (Tabela 1), fomentando o questionamento da economicidade do sistema.

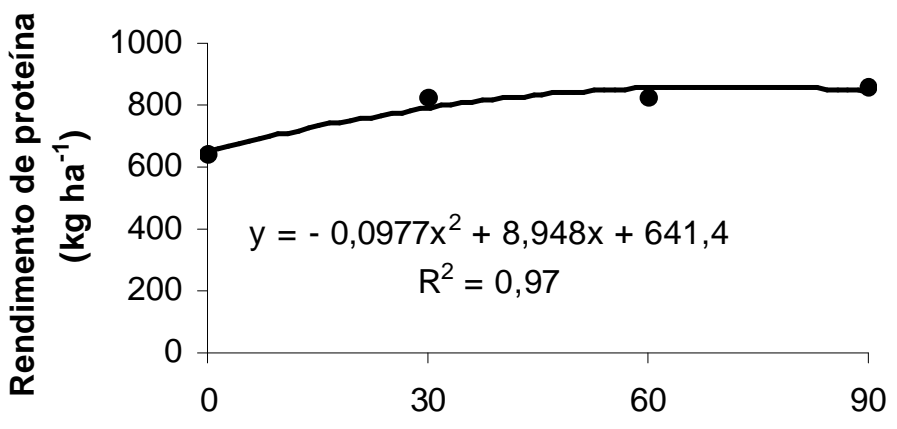

Doses de Potássio $\left(\mathrm{kg} \mathrm{ha}^{-1}\right)$

FIGURA 2 - Desdobramento das interações entre doses de potássio e o espaçamento de $30 \mathrm{~cm}$ no rendimento de proteína dos grãos de guandu. Selvíria, MS, 2005.

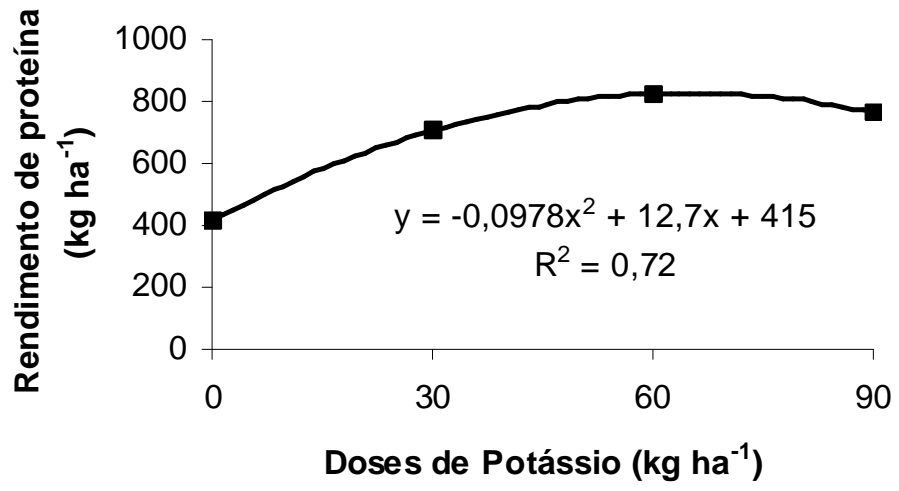

FIGURA 3 - Desdobramento das interações entre doses de potássio e a dose de $40 \mathrm{~kg} \mathrm{ha}^{-1}$ de fósforo no rendimento dos grãos de guandu. Selvíria, MS, 2005.

De acordo com os resultados observa-se que os tratamentos responsáveis por maior incremento em quantidade de proteína bruta nos grãos não coincidem com os tratamentos mais positivos ao rendimento de proteína por área. Isso ocorreu porque o rendimento de proteína variou diretamente em relação ao rendimento de grãos, portanto as duas variáveis responderam de forma semelhante aos tratamentos. GOMES JÚNIOR et al. (2005) também observaram que os tratamentos que proporcionaram maior incremento de proteína bruta não foram comuns aos tratamentos mais positivos ao rendimento de proteína por hectare em feijoeiro.

\section{CONCLUSÕES}

1) O espaçamento de $50 \mathrm{~cm}$ proporciona grãos com maior porcentagem de proteína, no entanto o espaçamento de $30 \mathrm{~cm}$ proporciona maior rendimento de grãos e maior rendimento de proteína por área.

2) A dose de $40 \mathrm{~kg} \mathrm{ha}^{-1}$ de fósforo proporciona grãos com maior porcentagem de proteína e o melhor rendimento de proteína por hectare é obtido na dose de $120 \mathrm{~kg} \mathrm{ha}^{-1}$.

3) A dose de $60 \mathrm{~kg} \mathrm{ha}^{-1}$ de potássio proporciona maior rendimento de proteína por área. 


\section{REFERÊNCIAS}

1. AHLAWAT, I.P.S.; SARAF, C.S. Response of pigeon pea (Cajanus cajan L. Millsp.) to plant density and phosphorus fetilizer under dryland conditions. Journal of Agricultural Science, v. 97, p. 119-124, 1981.

2. ASSOCIATION OF OFFICIAL ANALYTICAL CHEMISTS - AOAC. Official methods of analysis. 16 ed. Washington: AOC, 1995.

3. BANZATTO, D.A.; KRONKA, S. do N. Experimentação agrícola. 4. ed. Jaboticabal: FUNEP, 2006. 237 p.

4. BARCELOS, M.F.P.; TAVARES, D.Q.; MIRANDA, M.A.C.; GERMER, S.P.M. Aspectos químicos e bioquímicos de leguminosas enlatadas em diferentes estádios de maturação. Ciência e Tecnologia de Alimentos, v. 19, n. 1, p. 59-72, 1999.

5. EMBRAPA. EMPRESA BRASILEIRA DE PESQUISA AGROPECUÁRIA. Centro Nacional de Pesquisa de Solos. Sistema brasileiro de classificação de solos. Rio de Janeiro: EMBRAPA/CNPS, 1999. 412 p.

6. GOMES JUNIOR, F.G.; LIMA, E.R.; LEAL, A.J.F.; MATOS, F.A.; SÁ, M.E.; HAGA, K.I. Teor de proteína em grãos de feijão em diferentes épocas e doses de cobertura nitrogenada. Acta Scientiarum, v. 27, n. 3, p. 455-459, 2005.

7. HAAG, H.P. O guandu como planta forrageira. In: Forragens na seca: algaroba, guandu e palma forrageira. Campinas: Fundação Cargill, 1986. p. 25-104.

8. HERNANDEZ, F.B.T.; LEMOS FILHO, M.A.F.; BUZZETTI, S. Software Hidrisa e o balanço hídrico de Ilha Solteira. Ilha Solteira: UNESP/FEIS/Área de Hidráulica e Irrigação, 1995. 45 p.

9. HONDA, C.S.; HONDA, A.M. Cultura da alfafa. São Paulo: Livroceres, 1990. 245 p.

10. JOHANSEN, C. Pigeonpea: mineral nutrition. In: NENE, Y.L.; HALL, S.D.; SHEILA, V.K. The pigeonpea. Cab international. International crops research institute for the semi-arid tropics, 1990. Cap. 9. p. 209-231.

11. JONES, M.B.; FREITAS, L.M.M. Respostas de quatro leguminosas tropicais a fósforo, potássio e calcário num latossolo vermelho-amarelo de campo cerrado. Pesquisa Agropecuária Brasileira, n. 5, p. 91-99, 1970.

12. LOURENÇO, A J.; DELISTOIANOV, J. Desempenho de bovinos em pastagem de capim-colonião com acesso ao banco de proteína de guandu. Revista Brasileira de Zootecnia, v. 22, n. 6, p. 902-911, 1993.

13. MALAVOLTA, E.; VITTI, G.C.; OLIVEIRA, S.A. Avaliação do estado nutricional das plantas: princípios e aplicações. Piracicaba: POTAFÓS, $1997.319 \mathrm{p}$.

14. MIZUBUTI, I.; SOUZA, L.; BIONDO JÚNIOR, O.; IDA, E. Propriedades químicas e cômputo químico dos aminoácidos da farinha e concentrado protéico de feijão guandu (Cajanus cajan (L.) Millsp). Boletim Centro de Pesquisa de Processamento de Alimentos, v. 18, n. 2, p. 237-248, 2000.

15. OGUNWALE, J.A.; OLANIYI, J.K. Response of pigeon pea (Cajanus cajan L. Millsp.) to phosphorus on a phosphorus marginal soil in Nigeria. East African Agricultural Forestry Journal, v. 43, p.274-280, 1978.

16. SALUNKHE, D.K.; CHANCELLOR, V.; CHAVAN, J.K.; KADAM, S.S. Pigeonpea as an important food source. Food Science and Nutrition, v. 23, n. 2, p.103-145, 1986.

17. SCHAMNE, J.A.; RONZELLI JÚNIOR, P.; DAROS, E.; KOEHLER, H.S. Arranjos espaciais para a cultura do feijoeiro em sistema de semeadura convencional. Scientia Agraria, v. 2, n. 1-2, p. 99-105, 2001.

18. SEIFFERT, N. F. Manejo de leguminosas forrageiras arbustivas de clima tropical. In: SIMPÓSIO SOBRE MANEJO DA PASTAGEM, 9, Piracicaba, 1988. Anais. Piracicaba: FEALQ, 1988. p. 285-314.

19. SEIFFERT, N.F.; MONDARDO, E.; SALERNO, A.R.; MIRANDA, M. O potencial do guandu. Agropecuária catarinense, v. 1, n. 4 , p. $18-20,1988$.

20. SEIFFERT, N.F.; THIAGO, L.R.L.S. Legumineira: cultura forrageira para produção de proteína. Campo Grande, EMBRAPA CNPGC, 1983. 52 p. (Circular Técnica, 13).

21. SHARMA, D. Intentional adaptation of pigeonpeas. In: INTERNATIONAL WORKSHOP ON PIGEONPEAS, 1980, Pantacheru. Proceedings. Pantacheru: ICRISAT, 1981. p. 137-146.

22. STODDART, L.A.; SMITH, A.D. Range management. 2. ed. New York: Mc Graw Hill, 1955. p. 258-276.

23. SINGH, U.; JAMBUNATHAN, R. Methods for the estimation of protein in Pigeonpea (Cajanus cajan (L.) Millsp.) and the relationship between whole grain and dhal protein contents. Journal Science Food Agricultural, v. 32, p. 705-710, 1981.

24. TEIXEIRA, J.P.F.; SPOLADORE, D.S.; BRAGA, N.R.; BULISANI, E.A. Composição química de feijão guandu cultivar kaki. Bragantia, v. 44, n. 1, p. 453-457, 1985.

25. VALARINI, M.J.; GODOY, R. Contribuição da fixação simbiótica de nitrogênio na produção de guandu (Cajanus cajan (L.) Millsp). Scientia Agricola, v. 51, n. 3, p. 500-504, 1994.

26. WUTKE, E.B. Caracterização fenológica e avaliação agronômica de genótipos de guandu (Cajanus cajan L. Millsp.). Piracicaba, 1987. 164 f. Dissertação (Mestrado) - Universidade de São Paulo, Escola Superior de Agricultura "Luiz de Queiroz".

27. WUTKE, E.B.; MIRANDA, M.A.C.; AMBROSANO, E.J.; BRAGA, N.R.; BULISNI, E. A. Guandu - Cajanus cajan L. Millsp. In: FAHL, J.I.; CAMARGO, M.B.P, PIZZINATTO, M.A.; BETTI, J.A.; MELO, A.M.T., DE MARIA, I.C.; FURLANI, A.M.C. (Eds.). Instruções agrícolas para as principais culturas econômicas. 6. ed. Campinas: Instituto Agronômico, 1998. p. 288-289. (Boletim Técnico, 200).

28. ZONTA, E.P.; MACHADO, A.A. SANEST: Sistema de análise de variância por microcomputadores. Pelotas: UFPel, 1991. $104 \mathrm{p}$

Recebido em 19/03/2007

Aceito em 01/10/2007 
